\title{
Psicólogos na Estratégia Saúde da Família: Caminhos Percorridos e Desafios a Superar
}

Psychologists In The Family Health Strategy:

Paths Traversed And Challenges To Overcome

Psicólogos En La Estrategia Salud De La Familia:

Caminos Enfrentados Y Desafíos A Superarse
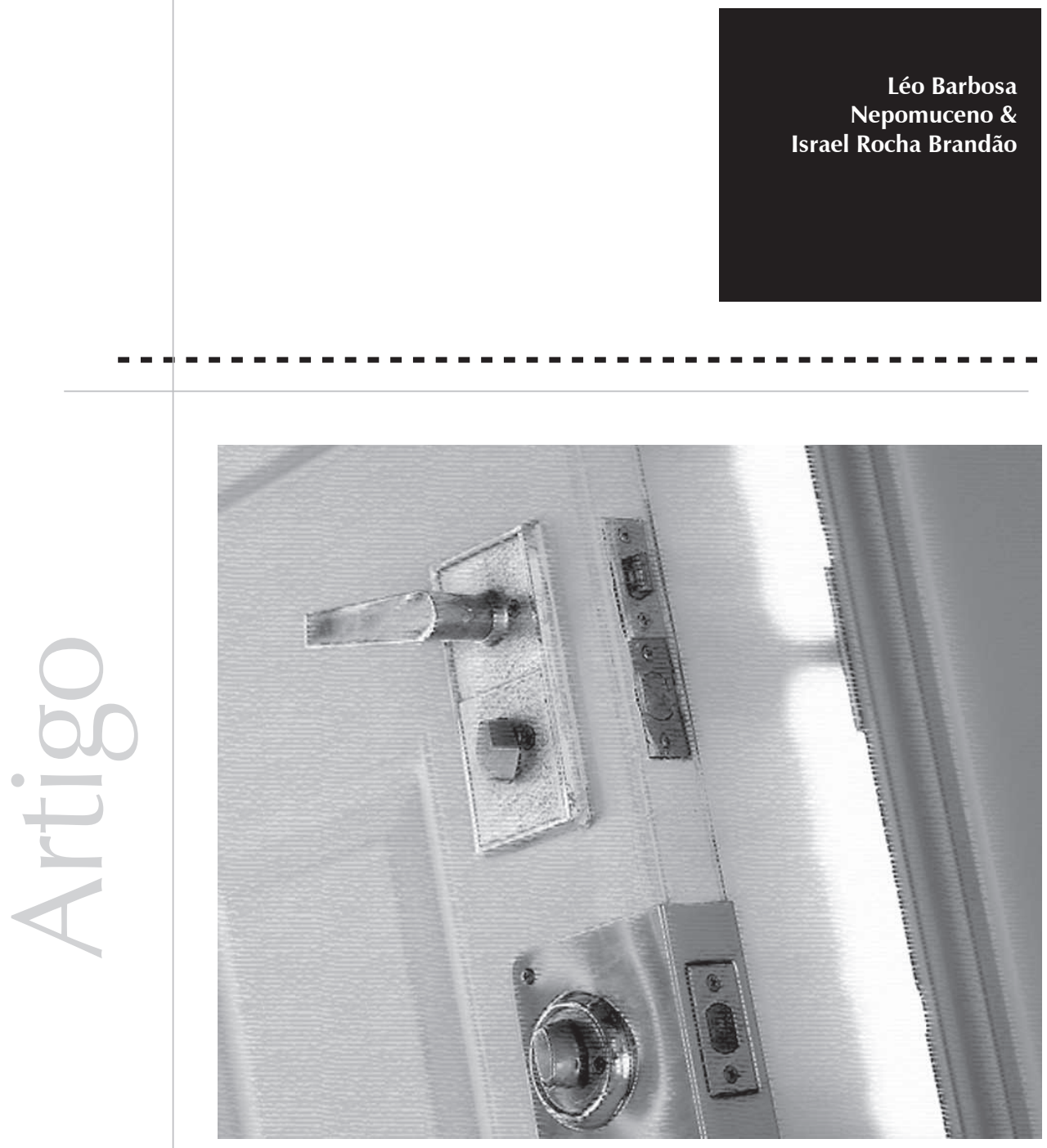
Resumo $\mathrm{O}$ artigo relata pesquisa de abordagem qualitativa sobre a inserção da Psicologia na Estratégia de Saúde da Família (ESF) do Sistema Único de Saúde (SUS) do Brasil, e faz uso de questionário aberto junto a sete psicólogos inseridos em residências multiprofissionais em Saúde da Família de quatro cidades brasileiras (Sobral, Rio de Janeiro, São Paulo, Florianópolis), além de anotações de campo feitas pelo autor principal, em sua experiência como psicólogo-residente, para investigar temas relevantes para esse novo campo de atuação psicológica. A partir do material empírico investigado, o artigo destaca o papel da Psicologia no SUS e na ESF, questiona os desafios e dificuldades enfrentadas e sistematiza atividades que foram desenvolvidas pelos participantes da pesquisa. Por fim, questiona o papel historicamente ocupado pela Psicologia na saúde pública, apontando a emergência de uma prática voltada para a mudança social como caminho fértil de inserção dos psicólogos na Atenção Primária à Saúde.

Palavras-chave: Psicologia. Atenção Primária à Saúde. Saúde da Família. Sistema Único de Saúde.

Abstract: This article reports a qualitative approach research on the integration of psychology in the Family Health Strategy (ESF) of the Unified Health System (SUS) in Brazil. A questionnaire with seven psychologists enrolled into multiprofessional residence courses in the Family Health Strategy from four cities in Brazil and field notes by the main author, in his experience as a psychologist and resident, were used to investigate issues that are relevant to this field of psychological performance. Considering the empirical investigation, the article highlights the role of psychology in the SUS and ESF, discusses the advances and difficulties found and systematizes activities that were developed by the participants. Finally, the research questions the role historically held by the Public Health Psychology, pointing to the emergence of a work toward social change as a fertile way to integrate psychologists into the Primary Health Care.

Keywords: Psychology. Primary Health Care. Family Health. Unified Health System.

Resumen: El artículo relata la investigación sobre la inserción de la Psicología en la Estrategia de Salud de la Familia (ESF) del Sistema Único de Salud (SUS) de Brasil. Se utiliza de abordaje cualitativo, uso de cuestionario abierto junto a siete psicólogos insertados en Residencias Multiprofesionales en Salud de la Familia de cuatro ciudades brasileñas (Sobral, Río de Janeiro, San Pablo, Florianópolis) y anotaciones de campo llevadas a cabo por el autor principal, en su experiencia como psicólogo-residente, a fin de investigar temas relevantes a ese nuevo campo de actuación psicológica. A partir del material empírico investigado, el artículo destaca el papel de la Psicología en el SUS y en la ESF, cuestiona los desafíos y dificultades enfrentadas y sistematiza actividades que han sido desarrolladas por los participantes de la investigación. Por fin, cuestiona el papel históricamente ocupado por la Psicología en la Salud Pública, señalando la emergencia de una práctica destinada al cambio social como camino fértil de inserción de los psicólogos en la Atención Primaria a la Salud.

Palabras Clave: Psicología. Atención Primaria a la Salud. Salud de la Familia. Sistema Único de Salud.

Debates atuais que vêm se desenvolvendo no campo da saúde pública trazem à tona uma reflexão de alcance internacional de crítica ao paradigma biomédico em saúde e a seus elementos: curativismo, biologicismo, unicausalidade, mecanicismo, especialização e individualismo (Westphal \& Santos, 1999). Tal reflexão vem enfatizar a ampliação do conceito de saúde e a importância da responsabilidade e do "compromisso da sociedade com seus ideais de saúde" (Ferreira \& Buss, 2002, p.19). A ênfase na multiplicidade e na complexidade dos fatores existentes no processo saúde-doença-cuidado é resultado desse movimento de rupturas, que vem requisitar uma reestruturação das políticas de saúde e das práticas emergentes de um novo paradigma em saúde.
É dentro desse contexto que se debate a ampliação da inserção da Psicologia na Estratégia de Saúde da Família (ESF) como tema relevante e atual diante do progressivo avanço das práticas de Atenção Primária à Saúde (APS) no Sistema Único de Saúde (SUS) do Brasil. Como reflexo do avanço das políticas públicas de saúde, os saberes e as práticas da Psicologia passam a ser cada vez mais requisitados, bem como os de outras categorias profissionais da saúde. Como indícios da relevância da inserção de outros profissionais na ESF, podemos citar o desenvolvimento de diversos programas de residência multiprofissional em saúde no Brasil (Brasil, 2006) e a aprovação recente dos Núcleos de Apoio à Saúde da Família (NASF) como política de expansão da 
atenção integral à saúde na APS do SUS (Brasil, 2008). O próprio trajeto histórico da saúde pública, de progressiva aproximação a um conceito ampliado de saúde, vem requerer a construção de uma práxis sanitária necessariamente interdisciplinar, na qual os elementos psicológicos se tornaram fundamentais.

Diante de um contexto de abertura e de ampliação de sua inserção no SUS, a Psicologia se vê como herdeira de uma história marcada, em geral, por atuações incipientes e limitadas na saúde pública do Brasil. Tal afirmativa se ancora na produção científica sobre o tema (Dimenstein, 1998; 2001, 2003; Camargo-Borges \& Cardoso, 2005; Spink, 2003; Traverso-Yépez, 2001; Benevides, 2002, 2005; Yamamoto, 2005; Oliveira, Dantas, Costa, Gadelha, Ribeiro, \& Yamamoto, 2003) e no entendimento de que as contribuições dessa ciência e profissão são diversas e muito relevantes para o desenvolvimento do campo saúde.

A Psicologia é uma profissão recente (foi oficializada no Brasil apenas em 1962) que tem uma trajetória histórica na sociedade brasileira fortemente marcada por compromissos com as elites e com a manutenção do status quo (Bock, 2003; Yamamoto, 2003; Dimenstein, 2001). Assim, após a legalização da profissão no País, "a ênfase das atividades desse profissional se centrou, nas décadas seguintes, no trabalho autônomo, clínico, individual, curativo e voltado para uma clientela financeiramente privilegiada no acesso" (Camargo-Borges \& Cardoso, 2005, p. 28). A Psicologia constrói, nesse contexto, um acúmulo histórico-cultural de uma atuação profissional perpassada pela dicotomia corpo-mente, pelo trabalho isolado e uniprofissional, pela focalização em abstratos elementos mentais e pela reprodução descontextualizada da atividade clínica individual privativa (Traverso-Yépez, 2001). Atuando hegemonicamente nessa perspectiva, a profissão contribuiu mais para a manutenção do modelo biomédico do que para a sua transformação. No campo teórico, os fenômenos da esfera psíquica ou mental foram sendo abordados sem a devida consideração das dimensões sociais, econômicas e políticas específicas dos contextos em que o processo saúde-doençacuidado se constitui (Camargo-Borges \& Cardoso, 2005). Esse fazer limitado se deu, portanto, dentre outras razões, pela reprodução descontextualizada e ideológica dos modelos teórico-metodológicos e pela utilização de concepções abstratas de sujeito e de subjetividade, em que se operam dissociações entre o indivíduo e a área social, entre subjetividade e objetividade, entre singular e coletivo (Bock, 2003; Yamamoto, 2003; Oliveira et al., 2005; Dimenstein, 1998, 2001, 2003; Benevides, 2002, 2005).

Em um movimento histórico de mudanças que vem se configurando no setor saúde do Brasil, novos espaços são criados, como os NASF e os programas de residência multiprofissional em saúde, de modo que se possibilita uma participação maior dos psicólogos no SUS. Nesse processo, o profissional psicólogo se vê diante do despreparo histórico da categoria para desenvolver um trabalho em sintonia com os imperativos de mudança. Em particular, na realidade brasileira, um modelo de formação limitado ainda se apresenta como desafio para o avanço das práticas psi. Tal modelo de formação se caracteriza pela centralização excessiva na atividade clínica tradicional e na prática psicoterapêutica de longa duração, ainda apresentando restrições no que tange às inovações requeridas para o campo da saúde pública (Traverso-Yépez, 2001; Bernardes, 2007; Dimenstein \& Macedo, 2007). Diante dessa realidade, entidades de classe como a Associação Brasileira de Ensino em Psicologia (ABEP) vêm buscando estabelecer diretrizes nacionais para qualificar a presença dos psicólogos no SUS (2006), tomando como objeto de reflexões os 
projetos político-pedagógicos dos cursos de graduação em Psicologia. Por sua vez, mais especificamente interessado na ampliação de espaços para a inserção dos profissionais psicólogos na ESF do SUS, o Conselho Federal de Psicologia realizou, em 2008, o seminário nacional intitulado O Núcleo de Apoio à Saúde da Família e a Prática da Psicologia, problematizando os modos como a profissão pode aprofundar sua atuação e fortalecer a saúde pública brasileira a partir da APS (Conselho Federal de Psicologia, 2009).

Diante do exposto, podemos afirmar que uma ampla esfera de possibilidades e necessidades de atuação da Psicologia na saúde pública precisa ser debatida, de forma a se empreender significativas mudanças nos processos de formação e de atuação dos psicólogos. As limitações históricas dos processos de formação (Dimenstein, 2003; Traverso-Yepez, 2001; Bernardes, 2007) colocam-se como desafio a ser superado nas estratégias de mudança.

Segundo Regina Benevides (2005), para superar as lacunas existentes na interface Psicologia e SUS, a atuação do psicólogo deve estar sintonizada, em um nível macropolítico, com os princípios do SUS (universalidade, integralidade e equidade), e, em um nível micropolítico, apontar os processos de construção de subjetividades dos vários atores envolvidos no trabalho em saúde. Já Magda Dimenstein, ao discutir o componente do compromisso social na saúde coletiva, destaca que se trata, principalmente, "da transformação de tais profissionais em agentes de mudança a partir de um compromisso social perante o ideário do sistema de saúde e seus usuários" (2001, pp.57-58).

O SUS, portanto, apresenta-se como um desafio histórico para os psicólogos, desafio esse que requer não só uma participação profissional melhor instrumentalizada tecnicamente mas, sobretudo, a apreensão e o impulso do movimento de reforma sanitária que esse arcabouço institucional representa. Tal movimento resultou na consolidação da saúde como direito de todos e dever do Estado, através da conquista de um sistema de saúde universal, pautado na integralidade e na equidade da atenção e do cuidado. Nesse contexto, em que se reivindicam mudanças societárias, urge a necessidade de um trabalho voltado para a mudança das condições de vida da população que articule promoção da saúde e da cidadania. Uma nova relação da profissão é requisitada, e um novo tipo de posicionamento frente às questões sociais precisa ser construído.

O desafio requer lidar com uma concepção ampliada de saúde, que aponte múltiplas dimensões e caminhos de atuação. Cabe olharmos para a construção do SUS como incorporação e articulação de diversos movimentos e atores sociais no debate da saúde pública brasileira, entendendo os modos como o social se apresenta como determinante do processo saúde-doença-cuidado.

A criação do Programa de Saúde da Família (PSF) e seu desenvolvimento e ampliação para a ESF expressa, dentre outras questões, a busca de concretizar os preconizados princípios do SUS, aumentando o acesso e a qualidade dos serviços de saúde para a população, e racionalizando os gastos públicos. A ESF vem consolidando-se como política responsável pela APS no SUS e com a responsabilidade de ser um eixo estruturante no empreendimento da reestruturação do modelo de atenção à saúde (Camargo-Borges \& Cardoso, 2005). Configurando-se como APS, a ESF apresenta as características de: acessibilidade, ser o primeiro contato entre o usuário e o sistema de saúde, pautar-se no vínculo profissionalusuário, na atenção longitudinal e integral, na adstrição de clientela, na focalização na família e na orientação comunitária (Starfield, 2002; Andrade, Barreto, \& Bezerra, 2006; Camargo-Borges \& Cardoso, 2005). 
Partindo desse contexto, coloca-se como necessário empreendermos um permanente questionamento quanto à relevância social das práticas ensejadas pela ESF e das contribuições do psicólogo nesse campo e de como a prática desse profissional pode estar contribuindo de forma efetiva para a consolidação do SUS, como política social fundamental para o povo brasileiro. Assim, o presente artigo tem como objetivos: investigar as contribuições de psicólogos na ESF, sistematizar práticas desenvolvidas e discutir os desafios enfrentados pelos psicólogos nesse campo.

\section{Percurso metodológico}

Este artigo relata pesquisa realizada no exercício da residência multiprofissional em Saúde da Família (RMSF), entre maio de 2005 e abril de 2007, na cidade de Sobral, Ceará, e propõe-se a investigar o trabalho de psicólogos na ESF, contando com a significativa experiência dos autores na atenção e na formação em saúde nos mesmos cenários. Trata-se de pesquisa de campo exploratória, de abordagem qualitativa e de cunho etnográfico realizada a partir de informações construídas junto a psicólogos que fizeram RMSF em algumas cidades do Brasil.

Apoiamo-nos na concepção de que o conhecimento é "um produto histórico ancorado em contextos sociais e culturais específicos" (Spink, 2000, p. 19), na qual a pesquisa é considerada uma prática social historicamente situada. Na ontologia do presente estudo, incorporamos parte da concepção de sujeito implicado e militante, colocada por Emerson Mehry (2006), na qual o pesquisador é também partícipe da atividade social estudada. Ao desenvolver a pesquisa, portanto, deparamo-nos com um rico e ousado processo de autoanálise de nossa própria condição de sujeitos sociais participantes da experiência investigada.
A estratégia metodológica da pesquisa estruturou-se em dois eixos complementares: construção de informações através de questionários realizados junto a psicólogos residentes em diferentes programas de RMSF no Brasil e sistematização de informações contidas em diários e anotações de campo do autor principal, realizados no período de sua experiência como psicólogo residente. Construímos, portanto, um material empírico que aglutina elementos significativos da experiência intersubjetiva de psicólogos que trabalharam na ESF, em processo de residência multiprofissional em Saúde da Família. É importante destacar que os participantes da pesquisa inseriram-se em um processo de formação em serviço, discutido como padrão de excelência na formação pós-graduada voltada para o SUS, já que organiza o processo formativo a partir da problematização das experiências vivenciadas na prática cotidiana dos serviços de saúde (Brasil, 2006).

Os participantes da pesquisa foram 8 psicólogos: o autor principal (residente em Sobral), outros 4 residentes da RMSF em Sobral e 3 psicólogas residentes nas cidades de Rio de Janeiro, São Paulo e Florianópolis, sendo uma em cada experiência de RMSF dessas cidades. Foi realizada aplicação de questionário aberto junto a 7 (sete) dos participantes da pesquisa, contendo 13 questões (em anexo) que versaram sobre os temas: SUS, ESF e intervenção social. O contato para a participação na pesquisa foi feito em evento científico realizado no Rio de Janeiro, em agosto de 2006. O questionário foi respondido por correio eletrônico, e a pesquisa foi submetida e aprovada no Comitê de Ética em Pesquisa da Universidade Estadual Vale do Acaraú, cadastrada com o número FR103464.

A análise do material empírico produzido orientou-se pela interpretação dos questionários realizados, utilizando-se os diários e as anotações de campo como 
material complementar de suporte para a reflexão sobre os temas emergentes dos questionários. A análise temática foi utilizada como técnica de análise de conteúdo (Bardin, 1977) dos textos produzidos. Os temas que emergiram na análise do material construído foram organizados em dois principais macrotemas da pesquisa: Psicologia e SUS e Psicologia e ESF.

\section{Apresentação e discussão do material construído}

\section{Psicologia e SUS}

\section{O SUS visto pelos psicólogos participantes}

O SUS é compreendido como uma conquista social de relevância para o povo brasileiro, mas que apresenta contradições. Os participantes apontaram os aspectos positivos do SUS bem como as dificuldades para a concretização dos seus princípios doutrinários (universalidade, equidade e integralidade). Destacam eles que direitos sociais, no que tange à acessibilidade aos serviços de saúde, à universalidade e à integralidade da atenção ainda estão longe de se expressarem de modo ampliado no cotidiano dos serviços, restringindose a microcontextos de expressão parcial e circunstancial dos direitos quando da construção de laços afetivos entre usuários e profissionais. O SUS também é percebido como avanço na política sanitária, por revelar-se como mecanismo impulsionador de mudança social, ou seja, como proposta que institui novos modos de sociabilidade, principalmente, pelos mecanismos de participação e de controle social.

Ênfase, portanto, fora dada aos mecanismos de participação e controle social preconizados pelo SUS. Estes foram destacados como fundamentais para o avanço das práticas de saúde. Nossas notas de campo mostram que tais mecanismos democráticos se fortalecem, primordialmente, nas experiências de participação dos usuários na cogestão cotidiana dos serviços, que potencializam sujeitos capazes de se colocar de modo mais ativo e envolvido na melhoria das ações em saúde.

Os psicólogos participantes percebem a existência de um projeto democrático de sociedade, que se articula à concretização dos princípios doutrinários e organizativos do SUS, agora diante de grandes desafios. Entre eles, o tema da participação social aparece como eixo de destaque neste estudo.

A defesa da participação da sociedade nos processos de formulação da atuação das unidades de saúde foi (embora deveria ser mais valorizada) a grande conquista da democracia brasileira. Proporciona, assim, uma tomada de posicionamento enquanto cidadãos, um posicionamento que necessita ecoar as várias vozes presentes nos mais diversos cenários. (Participante, RMSF-Rio de Janeiro).

A potencialização dos modos de participar do SUS se evidencia como um instrumento para promover a democracia no Brasil e, portanto, como desafio colocado à prática psicológica no SUS. Diante desse desafio, concebemos que a participação social, adotando uma perspectiva de educação popular (Vasconcelos, 2001, 2009), deve tomar como ponto de partida as experiências de aproximação e diálogo entre profissionais e usuários, reorientando as práticas, desobstruindo e fortalecendo a relação entre os serviços e os movimentos sociais-comunitários. A participação social, assim, busca demarcar espaços importantes na redefinição de práticas, podendo influir de modo significativo na potencialização da vida social.

\section{Desafios colocados à Psicologia no SUS}

O amadurecer de discussões nascidas na inserção da Psicologia no SUS expressa alguns 
dos desafios para o avanço da profissão nesse campo. Os participantes da pesquisa ressaltaram como necessidades para o aprimoramento da Psicologia: apropriação do tema das políticas públicas, discussão teórica e exercício prático em processos de trabalho interdisciplinar, reflexão sobre os princípios do SUS e seu contexto histórico, ampliação e renovação das práticas clínicas, discussão e envolvimento com questões sociais e políticas e desenvolvimento do campo da Psicologia comunitária e dos trabalhos com grupos. Vejamos o seguinte discurso de uma participante:

\begin{abstract}
A Psicologia, assim como as demais categorias profissionais da saúde, deveria investir mais na sua formação para atuação multiprofissional, e quem sabe interdisciplinar, e também um maior preparo para lidar com políticas públicas. Outra necessidade que percebo é uma maior aproximação com a Psicologia comunitária [...] (Participante, RMSF-SP).
\end{abstract}

A necessidade de aprimorar a relação entre a Psicologia e as políticas públicas foi um aspecto significativo nas respostas, revelando a pouca tradição dos trabalhos da Psicologia nesse campo e a pouca compreensão das formas de estruturação, desenvolvimento, gestão e avaliação de tais políticas. No caso das políticas públicas de saúde, o desafio da interdisciplinaridade perpassa o processo de inserção da profissão no SUS. Compreendemos que o destaque dado à necessidade de aprimoramento no campo da Psicologia comunitária manifesta um imperativo colocado no cotidiano da ESF, o de melhor lidar com os fenômenos psicológicos forjados na complexidade do contexto comunitário. Os diários de campo também corroboraram essa reflexão.

A análise do material produzido nos questionários também aponta a necessidade de elaboração de novos modelos clínicos capazes de articular elementos subjetivos e objetivos, em que a dimensão pessoal e comunitária se imbricam. Evidenciou-se um olhar crítico dos participantes frente aos modelos clínicos tradicionais, historicamente hegemônico nas práticas psi. Tais modelos de trabalho psicológico, principalmente o da psicoterapia de longa duração, foram percebidos, na experiência dos autores na ESF, como ineficazes no enfrentamento de questões sociais e coletivas colocadas pelo trabalho no SUS. Nesse aspecto, as críticas feitas pelos autores citados (Traverso-Yépez, 2001; Bernardes, 2007; Dimenstein \& Macedo, 2007) ainda permanecem atuais.

\section{O papel da Psicologia no SUS}

É recorrente nas respostas dos participantes a busca por um tipo de Psicologia capaz de contribuir para uma visão ampliadora sobre as demandas trazidas pelos usuários, considerando os contextos de inserção sociocultural dos indivíduos e dos coletivos, bem como os vários fatores que interagem no processo saúde-doença-cuidado.

Uma psicologia que abranja em sua concepção o conceito ampliado de saúde, em sintonia com condições de vida, qualidade de vida, numa perspectiva ampliada, visão holística de mente e corpo.[...] O papel também deve ser o de trazer contribuições a usuários e trabalhadores de saúde na busca pelo rompimento pela mera patologizaçao do indivíduo, e na compreensão com o contexto, compartilhando reflexões e possibilidades de trabalho (Participante 1, RMSF-CE).

Tal visão ampliadora é destacada como superação de modelos clínicos biomédicos patologizantes, que se restringem à cura de sintomas e doenças. O papel diferencial da Psicologia situa-se em uma ampliação da capacidade de ver e de escutar os indivíduos e coletivos, considerando potencialidades de saúde, criando espaços de reflexão e diálogo capazes de fomentar a expressão de não ditos e de abordar dimensões profundas da saúde, do adoecimento e da recuperação. 
Uma tarefa que se destaca direta e indiretamente nas respostas é a de desenvolver uma reflexão etiológica crítica sobre as enfermidades que acometem a população. A abordagem dos determinantes do sofrimento individual e coletivo aparece como eixo orientador de novos modos de atuar junto aos problemas de saúde da população. A Psicologia, portanto, situase na busca de aprimoramento do olhar e da intervenção sobre o contexto social e os fatores sociopsicológicos, que estão interligados na base das necessidades e dos potenciais de saúde da população a ser assistida.

Nesse ínterim, é destacada também a importância da Psicologia no olhar para as interações que o usuário tem no sistema de saúde, para as relações entre os profissionais de saúde e para as destes com os usuários. As formas de organização do trabalho em saúde apresentam-se como forma de atuação relevante para os psicólogos, na busca de organizar serviços mais satisfatórios para profissionais e usuários. O papel da Psicologia no SUS, portanto, aparece ligado a um conceito ampliado de saúde, ao desenvolvimento de uma visão ampliada sobre as interações presentes no processo saúde-doença e no trabalho em saúde.

\section{A Psicologia e a ESF}

\section{A ESF vista pelos psicólogos participantes}

A ESF é percebida como uma política relevante para a concretização das mudanças no modelo de atenção à saúde no Brasil, vista como um caminho possível para a efetivação do SUS. Alguns elementos constituintes e operacionais foram destacados como diferenciais importantes das ações da ESF; são eles: a adstrição de clientela, que demarca a população a ser atendida, a territorialização, que estrutura as ações a partir da base territorial-comunitária e o trabalho em equipe multiprofissional, que possibilita o compartilhamento de saberes e práticas e a busca ativa dos serviços na resolução de problemas recorrentes. Tais elementos foram considerados dispositivos organizativos com os quais os trabalhadores podem fortalecer a interação com a população usuária e construir vínculos e relações de corresponsabilidade ao lidar com os problemas e potenciais de saúde comunitária.

Destacou-se o poder da ESF de promover novas práticas de saúde fugindo do modelo tradicional (médico-centrado, focado em patologias e nos procedimentos queixasconduta). Para tal construção inovadora das práticas, foram destacados a importância do planejamento das ações e o fortalecimento das perspectivas de prevenção de doenças e de promoção da saúde. Para os participantes da pesquisa, a ESF contribui para a construção de um conhecimento mais aguçado sobre as doenças, agravos e necessidades de saúde no território.

Em linhas gerais, a ESF aparece nas respostas como facilitadora de experiências de atuação em vários âmbitos, fugindo da restrição aos campos do acompanhamento ambulatorial e à fragmentação decorrente da especialização. No entanto, destacaram-se também dificuldades percebidas no trabalho na ESF, as quais vêm impedindo a concretização dos processos de mudança buscados. Os participantes colocam que, muitas vezes, as práticas tradicionais (centradas no modelo biomédico de atenção) aparecem como inovação e avanço, apenas pelo fato de "serem ESF", ou seja, muitas vezes, o que se evidencia no trabalho da ESF é uma mudança meramente retórica que, inclusive, obscurece e paralisa o processo de mudanças a serem empreendidas. O discurso seguinte aborda esse tema: 
A ESF é uma estratégia que busca romper o modelo hospitalocêntrico, na perspectiva curativa e médico-centrada, que aproxima os profissionais da realidade vivenciada pelos usuários, que procura ousar nessa relação, profissional de saúde-usuário. Entretanto, é uma política que entra no cenário de disputas do SUS no rol de prioridades orçamentárias e que, muitas vezes, se fortalece como estratégia estruturante, esquecendo-se da complexidade das necessidades de saúde dos usuários. Acredito que seja uma estratégia que, por si só, não rompe as estruturas hegemônicas, que, muito pelo contrário, pelo fato de estar nesse lugar de inovação, deve ser amplamente discutida, com críticas contundentes, pois verifica-se muita reprodução de 'velhas-novas' práticas (Participante 2, RMSF-CE).

A falta de qualificação dos profissionais foi ressaltada como elemento-chave dessa perpetuação de práticas antigas, como a focalização nos procedimentos médicocentrados, a fragmentação dos processos de trabalho (pouco trabalho interdisciplinar), a falta de planejamento para organização da demanda, a pouca atenção dedicada às ações de prevenção e de promoção da saúde e a baixa participação dos usuários nas ações ensejadas pelos serviços. É necessário também destacar, como observado nos diários de campo, que a renovação das práticas coloca em cheque a estrutura de poder vigente nos centros de saúde da família, impondo certo tensionamento para a mudança das regras do jogo de disputas interprofissionais. E, nesse contexto micropolítico, nem todos os trabalhadores estão interessados nas inovações.

Aqui, identificamos na ESF características de um processo de mudanças progressivas postas em marcha, no qual fica patente o conflito com o velho modelo biomédico, com sua cultura historicamente instaurada no meio dos profissionais e da população usuária. Cabe, portanto, questionarmos permanentemente o poder da ESF a fim de instituir mudanças significativas para a concretização do SUS. A ausência de apreciação crítica dessa política pode fazer com que apenas se maqueie a permanência do modelo tradicional. Na experiência vivenciada pelos autores, ficou evidente a necessidade do fortalecimento das políticas de educação permanente dos profissionais, de maior aproximação e interação com os usuários e de uma permanente avaliação crítica do chamado caráter inovador da ESF.

\section{Trabalhos realizados pelos psicólogos na ESF}

Desenvolvemos, aqui, uma sistematização das ações desenvolvidas pelos psicólogos na ESF. As categorizações que fizemos agrupam formas de atuações descritas de forma semelhante, buscando organizar as ações listadas pelos participantes da pesquisa nos diversos contextos de experiência dos psicólogos na ESF. As ações abaixo citadas são geralmente construídas em trabalho multiprofissional, em que outras profissões e saberes podem encontrar-se interligados. Vejamos as ações:

Territorialização e planejamento local de saúde: realizadas necessariamente por toda equipe de saúde da família para reconhecer o contexto geográfico, ecológico, socioeconômico, entrar em contato com as necessidades e potenciais de saúde da comunidade e estruturar plano de ação. Advindo de um processo coletivo de leitura da realidade, o planejamento local de saúde deve enfrentar o desafio de contar com a participação ativa da população tanto na elaboração como no processo de avaliação e de execução das ações.

Ações de acolhimento do centro de saúde da família: atividades que incluem a recepção das pessoas no centro de saúde da família, possibilitando escuta ampliada de necessidades e buscando estruturar planos terapêuticos individuais e coletivos atrelados aos diversos níveis de atenção do sistema de saúde. 
Visitas domiciliares: ações de acolhimento, avaliação diagnóstica, acompanhamento terapêutico, aconselhamento psicológico e inserção familiar e comunitária realizadas através de visitas às moradias dos usuários.

Ações de suporte à saúde mental: essas ações têm o caráter de prevenção, de promoção da saúde, de tratamento e de reabilitação, e buscam o acompanhamento de indivíduos e grupos, articulando-se a ações desenvolvidas por outros dispositivos de assistência na Rede de Atenção à Saúde Mental. Nesse campo específico, vejamos as ações desenvolvidas: atendimento individual de casal e de famílias: ações de acompanhamento psicoterapêutico, aconselhamento psicológico, pronto atendimento psicológico, psicoterapia breve, terapia de crise, etc; atende a demandas das diversas idades (crianças, adolescentes, adultos e idosos) e lida, direta ou indiretamente, com diversos níveis de gravidade dos transtornos; grupos terapêuticos: atendimento em grupo de pessoas para acompanhamento em nível terapêutico; atende também a diversas idades; triagem em saúde mental: acolhimento, escuta e encaminhamento de demandas de sofrimento psíquico que chegam ao Centro de Saúde da Família; grupos de crescimento pessoal: grupo de promoção da saúde mental, no qual se trabalha a expressão de sentimentos e emoções, o compartilhar de problemas e as potencialidades encontradas na comunidade e na família bem como o fortalecimento dos laços de amizade e compromisso; participação nas interconsultas de psiquiatria: referem-se à participação do profissional psicólogo nas atividades de preceptoria de especialidade em psiquiatria (perspectiva de matriciamento e apoio às equipes de saúde da família); essa participação teve o propósito de fortalecer a ampliação do olhar sobre as pessoas atendidas, de trocar experiências, discutir casos, traçar projetos terapêuticos individuais e coletivos e compartilhar ações de cuidado e dos processos de referência e contrarreferência; outras ações em saúde mental: interconsulta psicológica, interconsulta interdisciplinar, cartografia das famílias acometidas por transtornos mentais, grupos temáticos, de caminhada ou de produção e renda articulados com CAPS e hospitais psiquiátricos; Atividades nas escolas: articulação de ações de promoção da saúde e de prevenção de doenças na escola junto a grupos de jovens, crianças e adultos, bem como a construção de ações de desenvolvimento humano e de aprendizagem junto aos professores e coordenadores pedagógicos; atuação/facilitação em grupos da ESF: a participação dos psicólogos nesses grupos se deu a partir da facilitação de alguns encontros dos grupos regulares da ESF bem como do acompanhamento e da organização desses grupos junto à equipe multiprofissional. As atividades desenvolvidas revelavam várias perspectivas, que iam desde um trabalho de cunho mais pedagógico (na perspectiva da educação em saúde) até outros mais terapêuticos (grupos de tratamento de doenças crônicas).

Participação nos espaços de formação nas RMSFs: aqui nos referimos à potencialização das discussões, ao diálogo e aprofundamento dos temas de aprendizagem, surgidos nos encontros de formação pedagógica da RMSF. O saber da Psicologia, nesses espaços, veio nutrir o diálogo interdisciplinar.

Ações de educação permanente junto à equipe de saúde da família e aos profissionais do território: tais ações visaram à criação e à facilitação, pelo profissional psicólogo, de espaços de discussão e aprendizagem junto aos outros profissionais dos centros de saúde da família, de outras políticas públicas do território de saúde e de instituições locais. Nas ações, o profissional coordenava a atividade discutindo temas afins à Psicologia. 
Facilitação de grupo nas reuniões de equipes multiprofissionais: buscando facilitar a gestão participativa, a organização do trabalho e o desenvolvimento das relações interpessoais nas equipes que compõem a ESF. Podemos destacar os trabalhos desenvolvidos pelos psicólogos de facilitação de reuniões das equipes, de grupos com funcionários do centro de saúde da família, reuniões de residentes e encontros de integração e de planejamento de ações.

Ações comunitárias e de articulação de redes sociais: assessoria a movimentos sociais organizados como associações de moradores, lideranças comunitárias e grupos comunitários. Nessas atividades, buscouse fortalecer as práticas comunitárias de promoção da saúde, através do fomento à integração dos grupos e às ações, bem como o fortalecimento de grupos estratégicos para o desenvolvimento comunitário.

Consultoria a projetos sociais: ações de fortalecimento da intersetorialidade, assessorando projetos sociais dentro dos territórios da ESF, sejam de iniciativa pública, sejam privada. As ações de consultoria visaram a criar e a potencializar espaços de interação, avaliação, planejamento, organização das ações e aprendizagem dentro dos projetos sociais. Agindo assim, buscou-se potencializar os processos de cogestão dentro dos projetos, criar planos intersetoriais de atuação no território e aumentar a resolubilidade das políticas sociais existentes no lugar.

Outras ações de fomento à participação e controle social: mobilização e organização popular para participar das instâncias de deliberação política na comunidade, como conselhos, associações comunitárias e outros grupos sociais.

É notável, através do material empírico construído, a riqueza da caminhada já empreendida pela Psicologia na ESF. As ações citadas representam uma ampla gama das possibilidades de atuação e de contribuição que a Psicologia pode dar na ampliação da cobertura às necessidades de saúde da população e ao desenvolvimento da ESF. A Psicologia, aqui, se apresenta trabalhando com uma população de faixas etárias diversas, com um fazer ligado ao atendimento das demandas de sofrimento psíquico e transtornos mentais, mas também ligado aos processos de organização de coletivos, aos processos de interação e às ações que visam ao desenvolvimento humano e social. As intervenções psicológicas, na ESF, ligam-se tanto à prevenção e à promoção da saúde como ao tratamento e à recuperação, vinculando-se à construção de soluções de curto, médio e longo prazo para os diversos dilemas de saúde da comunidade.

\section{O papel da Psicologia na ESF}

O trabalho do psicólogo na ESF, como de outros profissionais inseridos recentemente, apresenta-se como diverso pela necessidade de adequação ao contexto local e de abrangência dos serviços. As possibilidades apontam uma atuação direta, como porta de entrada, junto a usuários e comunidades, como membro de equipe multiprofissional de uma área de pequena abrangência territorial ou em uma atuação de equipe de apoio matricial, responsável por uma área abrangente, instrumentalizando diversas equipes da ESF para melhor atender as demandas sociais.

No caso da presente pesquisa, os participantes notaram várias possibilidades e certos entraves para melhor desenvolvimento e definição do papel da Psicologia. Pudemos analisar experiências em que o psicólogo atuou como membro da equipe mínima de saúde da família (área de abrangência de 600 a 1000 famílias) e como membro de equipes multiprofissionais co-responsáveis por territórios mais abrangentes ligado a 
várias equipes mínimas (áreas de abrangência que variavam de 1000 a 8000 famílias), que desenvolveram trabalhos mistos de atuação direta junto a usuários e atuação de apoio matricial, supervisão e suporte às equipes de um ou mais centros de saúde da família. A definição do papel da Psicologia na ESF, portanto, dependerá das formas como os psicólogos vão se inserir nos sistemas de saúde municipais, sendo a área de abrangência um fator determinante para a resolubilidade das ações.

A experiência vivida revela a dificuldade de construir um fazer eficiente e resolutivo quando os territórios de abrangência se tornam maiores que quatro equipes mínimas de ESF - o que representa um profissional psicólogo para no máximo 4000 famílias.

Tomando essa variante como fundamental, a análise do material empírico da pesquisa revelou outro ponto crucial para o delineamento do papel e das possibilidades de atuação da Psicologia na ESF: a sua relação com as redes de atenção à saúde mental. Essa análise evidenciou que a existência de uma boa rede de atenção secundária e terciária para o atendimento das demandas de saúde mental é fundamental para a prática do psicólogo dentro da perspectiva da APS. Na presente pesquisa, a não existência de uma rede estruturada entre os diversos níveis de atenção em saúde mental limitou o papel da Psicologia às ações de tratamento de psicopatologias e de sofrimento psíquico próprios da atenção secundária ou terciária, restringindo o desenvolvimento de uma atuação mais ampliada. Para desenvolver uma atuação mais voltada para a consideração do coletivo, pautada na construção de significativos vínculos com os outros profissionais e com a comunidade, desempenhando um acompanhamento longitudinal e construindo dispositivos de prevenção e promoção da saúde próprios da APS, o psicólogo depende diretamente do aporte do sistema de saúde local em saúde mental.

Considerados os referidos desafios, o papel da Psicologia na ESF é identificado como bem mais amplo e abrangente do que as ações de tratamento-cura em saúde mental. Trata-se de um fazer vinculado a uma compreensão integral dos indivíduos, às suas redes de interação e às suas necessidades e potenciais de saúde, com olhar ampliado para as relações sociais, que se constroem nos modos de vida de famílias e comunidades.

A experiência investigada destacou as contribuições da Psicologia na criação de espaços de diálogo sobre as experiências de vida dos usuários em seus diversos aspectos, problematizando os modos de estar no mundo de grupos e pessoas inseridas nos contextos territoriais de abrangência da ESF. A atuação situa-se no processo de fomento à autonomia dos sujeitos concomitantemente aos processos de cuidado em saúde, fortalecendo processos de autocuidado, de cogestão participativa dos serviços e de transformação da realidade social vivenciada nos territórios. Dentro dessa perspectiva, são criados processos de trabalho, dispositivos de cuidado e modelos de intervenção psicológica que facilitem reflexões e vivências potentes tanto para a terapêutica de doenças como para o fortalecimento do desenvolvimento humano e social em diversos espaços do território de saúde.

\section{A Psicologia buscando mudanças sociais: problematizando os resultados}

O trabalho realizado na ESF pelos psicólogos participantes expressa a construção de novas perspectivas de atuação voltadas para uma ampliação do escopo de ações da profissão no campo da saúde pública brasileira. A análise da experiência de inserção da 
Psicologia na ESF nos permite pensar em uma progressiva superação das dicotomias expressas por Benevides $(2002,2005)$ entre clínica e política, entre Psicologia clínica e Psicologia social. Mesmo com certa reserva, podemos afirmar que se empreende, a partir da interface atual entre Psicologia e APS, a superação de certa cisão cartesiana entre mente e corpo denunciada recorrentemente por vários estudos (Spink, 1992; Dimenstein, 1998; Traverso-Yépez, 2001; Bock, 2003; Yamamoto, 2003).

Evidenciou-se, no presente estudo, o aumento da abrangência de atuação da categoria profissional, que busca cada vez mais contribuir para processos de mudança pessoal e social articulados às complexas dinâmicas sociais nos territórios da saúde. O tão criticado modelo de atuação clínico tradicional (Traverso-Yépez, 2001; Benevides, 2005; Dimenstein, 1998, 2001, 2003) parece estar sendo modificado com inovações que apontam a integração entre subjetividade e objetividade, indivíduo, família e comunidade. Os elementos facilitadores desse modelo de atuação mais ampliada podem ser encontrados nas práticas de interdisciplinaridade oriundas dos encontros com outros saberes e práticas de outros profissionais inseridos, bem como de usuários, grupos e comunidades.

Neste estudo, encontramos expressas vontades e ações para transformar o modelo tradicional de atuação psicológico, buscando contribuir para a realização de mudanças sociais. Emergem iniciativas de construção de um fazer mais próximo das questões sociais da realidade brasileira, rompendo o distanciamento e a alienação apontados por Ozella (1997), construindo um novo compromisso social reivindicado e problematizado por Dimenstein (2001) e iniciando a superação do elitismo e do individualismo criticado por outros estudos (Dimenstein, 2000; Bock, 2003; Yamamoto,
2003). As demandas sociais trazidas com a ESF instigam o profissional psicólogo a questionar o compromisso social da categoria e a elaborar novos modos de atuar no campo social.

Os trabalhos que impulsionam a mudança social foram identificados como aqueles capazes de lidar com questões como: mobilização popular, mudança de práticas de trabalho, compartilhamento de saberes, formação de redes de apoio e questões referentes às condições de vida da comunidade (habitação, educação, segurança, etc). Os participantes percebem o caráter de inovação de algumas práticas desenvolvidas quando estas desencadeiam ampliações nos modos como usuários e profissionais compreendem o processo saúde-doença-cuidado, considerando os elementos subjetivos da experiência de adoecimento e de cuidado relacionados às formas como os sujeitos vivem e transformam a realidade social cotidianamente. Tal inovação, paradoxalmente, é expressa na percepção da limitação e da vontade de superação das práticas atuais, bem como do caráter da tentativa de mudança do processo de trabalho do psicólogo. Segundo os participantes, novos modos de atuar, que apresentam bons resultados na mudança de vida das pessoas e de seu entorno, pautam-se na problematização da realidade e no questionamento dos modos de vida dos envolvidos no processo saúde-doençacuidado. As práticas que se aproximam dessa perspectiva, mais do que operar nas mudanças dos procedimentos técnicos tão necessários para a superação dos modelos clínicos tradicionais, ensejam a mudança de postura ética do profissional psicólogo, comprometendo-se com a luta por uma saúde pública de qualidade e com as histórias de vida compartilhadas no dia a dia dos serviços de saúde. Tais processos não são apenas reflexivos, mas envolvem situações vivenciais, integrando elementos cognitivos e 
afetivo-emocionais. O intuito da intervenção psicológica é fomentar a autonomia dos sujeitos envolvidos no trabalho da ESF, em um contexto de articulação dos diversos atores sociais envolvidos através de metodologias participativo-dialógicas.

A percepção da possibilidade e do dever do envolvimento da Psicologia no chamado trabalho social mostra que é necessário ampliar a capacidade de articulação e diálogo com usuários, famílias e grupos comunitários na criação de processos de trabalho nos espaços comunitários fortalecedores das redes sociais e da participação social nos serviços da ESF.

\section{Considerações finais}

A fim de concluir o texto, destacamos elementos importantes apreendidos nessa caminhada da Psicologia pelos campos abertos da ESF do SUS. É notável o caráter inovador de algumas práticas, que visam a superar antigos estigmas e limitações históricas da categoria na saúde pública brasileira. Mesmo diante de um movimento ainda incipiente de mudanças, é possível afirmar que as dicotomias mente-corpo, indivíduo-social, subjetividade-objetividade e clínica-política, abordadas pelos estudos supracitados, começam a ser trabalhadas pelos psicólogos, e, assim, vemos tais temas serem enfrentados no cotidiano dos serviços públicos de saúde. No entanto, a construção de uma nova cultura profissional, mais sintonizada com os imperativos de mudança do setor saúde, pautada em uma visão ampliada da saúde e do adoecer e em um amplo escopo de ações voltadas para o cuidado integral, somente nos parece possível após um aprofundamento das relações teoria-prática psicológica, constituindo novos solos epistemológicos para a práxis psicológica. Compreendemos ser necessário o fortalecimento de estratégias de ensino que articulem os saberes da Psicologia e da saúde coletiva de modo a possibilitar a formação de sujeitos interessados em construir um projeto científico-profissional comprometido com a efetivação dos princípios do SUS.

É inegável que ainda há muito que caminhar para consolidar novas práticas e modelos de atuação em Psicologia para o SUS em geral e, em especial, para a ESF. Tornouse, no entanto, expresso o movimento de mudanças que, pouco a pouco, vem buscando e alcançando modos mais efetivos de participar das transformações necessárias ao desenvolvimento do SUS. A pesquisa revelou que a inserção da categoria na ESF se dá em um movimento progressivo de superação pessoal e coletiva dos psicólogos envolvidos, que precisa ser fortalecido. Revela-se, com a ampliação da APS no SUS, um momento de transição em que os psicólogos se encontram revendo seus referenciais teóricometodológicos. É preciso que avancemos na identificação e na superação de desafios, é hora de trocarmos experiências, é momento de avançarmos na inserção da categoria na realidade social brasileira, de defendermos criticamente a consolidação de um SUS que ainda está por vir. 
1 Em que áreas da Psicologia você tem experiência (graduando e graduado)?

2 Quais as áreas de atuação que lhe interessam na RMSF?

3 O que você entende ser o papel da Psicologia no setor saúde?

4 Na sua opinião, o que o Sistema Único de Saúde (SUS) proporciona à sociedade brasileira?

5 Para você, em que área a Psicologia precisaria melhorar para atuar no SUS?

6 Como você vê a Estratégia de Saúde da Família (ESF) como política do SUS?

7 Que trabalhos você tem desenvolvido na ESF? Liste as ações que realiza.

8 O que você entende ser o papel da Psicologia na ESF?

9 O que a Psicologia deve aprimorar para potencializar sua atuação na ESF?

10 Como você vê as contribuições de seu fazer, como psicólogo, para a população com a qual trabalha?

11 Você acha que a Psicologia contribui para mudar a vida das pessoas? Se sim, como?

12 Você vê que o seu processo de trabalho na ESF contribui para a mudança social?

13 Que tipo de contribuições a Psicologia pode dar no campo da intervenção social na ESF?

Léo Barbosa Nepomuceno

Doutorando em Saúde Coletiva pela UFC/UECE/UNIFOR - Fortaleza, CE - Brasil.

Bolsista da Fundação Cearense de Apoio ao Desenvolvimento Científico e Tecnológico (FUNCAP).

E-mail: leobnepomuceno@hotmail.com

Israel Rocha Brandão

Doutor em Psicologia Social pela PUC-SP, Professor Adjunto da Universidade Estadual Vale do Acaraú (UVA),

Ceará - Brasil.

E-mail: israelbrandao@ig.com.br

Endereço para envio de correspondência:

Rua República da Armênia 900, Bairro Agua Fria, Fortaleza, Ceará. CEP: 60821-760

Recebido 29/6/2010, 1a Reformulação 21/7/2011, Aprovado 12/8/2011. 


\section{Referências}

Andrade, L. O. M. de, Barreto, I. C. de H. C., \& Bezerra, R. C. (2006). Atenção Primária à Saúde e Estratégia de Saúde da Família. In Campos, G.W.S.; Minayo, M.C.S.; Akerman, M.; Drumond Júnior, M.; Carvalho, Y.M. (Orgs.), Tratado de Saúde Coletiva. São Paulo: Hucitec; Rio de Janeiro: Editora Fiocruz.

Associação Brasileira de Ensino em Psicologia/ABEP. (2006). A presença qualificada no SUS como um desafio para a psicologia: propostas da oficina nacional da ABEP. Brasília: Ministério da Saúde/Ministério da Educação/Organização Panamericana de Saúde.

Bardin, L. (1977). Análise de conteúdo. Lisboa: Edições 70.

Benevides, R. (2002). Clínica e social: polaridades que se opõem/ complementam ou falsa dicotomia? In C. Rauter, E. Passos, \& R. Benevides (Orgs.), Clínica e política: subjetividade e violação dos direitos humanos. Rio de Janeiro: Editora Te Cora.

Benevides, R. (2005, maio/ago.). A psicologia e o Sistema Único de Saúde: quais interfaces? Psicologia \& Sociedade, $17(2), 21-25$

Bernardes, J. S. (2007). A psicologia no SUS 2006: alguns desafios na formação. In M. J. P. Spink, (Org.), A psicologia em diálogo com o SUS: prática profissional e produção acadêmica. São Paulo: Casa do Psicólogo.

Bock, A. (2003). Psicologia e sua ideologia: 40 anos de compromisso com as elites. In A. Bock (Org.), Psicologia e compromisso social. São Paulo: Cortez.

Brasil. Ministério da Saúde. Secretaria de Gestão do Trabalho e da Educação na Saúde. Departamento de Gestão da Educação na Saúde. (2006). Residência multiprofissional em saúde: experiências, avanços e desafios (414 p.). Brasília: Ministério da Saúde. (Série B. Textos Básicos de Saúde).

Brasil. Ministério da Saúde. (2008). Portaria no 154, de 24 de janeiro de 2008. Núcleos de apoio à saúde da família. Recuperado em 06 de setembto, 2009 de < http://duvas. saude.pi.gov.br/sistemas_de_informacao/doc_tec_leg/siab/ portaria-n-154-nasf.pdf>

Camargo-Borges, C., \& Cardoso, C. L. (2005, maio/ago.). A psicologia e a Estratégia Saúde da Família: compondo saberes e fazeres. Psicologia \& Sociedade, 17(2), 26-32.

Conselho Federal de Psicologia. (2009). A prática da psicologia e o Núcleo de Apoio à Saúde da Família. Brasília: Autor.

Dimenstein, M. (1998). O psicólogo nas unidades básicas de saúde: desafios para a formação e atuação profissionais. Estudos de Psicologia, 3(1), 53-81.

Dimenstein, M. (2000). A cultura profissional do psicólogo e o ideário individualista: implicações para a prática no campo da assistência pública à saúde. Estudos de Psicologia, 5(1), 95-121.

Dimenstein, M. (2001, jul./dez.). O psicólogo e o compromisso social no contexto da saúde coletiva. Psicologia em Estudo, 6(2) $57-63$

Dimenstein, M. (2003). Los (des)caminos de la formación profesional del psicólogo en Brasil para la actuación en la salud pública. Rev. Panam. Salud Publica/Pan. Am. J. Public. Health, 13(5), 341-345.

Dimenstein, M., \& Macedo, J. P. (2007). Desafios para o fortalecimento da psicologia no SUS: a produção referente à formação e inserção profissional. In M. J. P. Spink (Org.),
A psicologia em diálogo com o SUS: prática profissional e produção acadêmica. São Paulo: Casa do Psicólogo.

Ferreira, J. R., \& Buss, P. M. (2002). O que o desenvolvimento local tem a ver com a promoção da saúde? In R. Bodstein, L. Zancan, \& W. Marcondes (Orgs.), Promoção da saúde como caminho para o desenvolvimento local:a experiência de Manguinhos. Rio de Janeiro: ABRASCO/FIOCRUZ.

Merhy, E. E. (2006). O conhecer militante do sujeito implicado: o desafio em reconhê-lo como saber válido. Recuperado em 07 de julho de 2006 de <http://www.uff.br/saudecoletiva/ professores/merhy/capitulos-02.pdf > .

Oliveira, I. F. de, Dantas, C. M. B., Costa, A. L. F., Gadelha, T. M. S., Ribeiro, E. M. P., \& Yamamoto, O. H. (2005). A psicologia, o Sistema Único de Saúde e o Sistema de Informações Ambulatoriais: inovações, propostas e desvirtuamentos. Interação em Psicologia, 9(2), 273-283.

Ozella, S. (1997). Alguns estudos sobre a formação dos psicólogos 1974-1994. Psicologia e Educação, (5), 57-71.

Spink, M. J. (2003). Psicologia social e saúde: práticas, saberes e sentidos. Petrópolis, RJ: Vozes.

Spink, M. J. (2000). A ética na pesquisa social: da perspectiva prescritiva à interanimação dialógica. Psico, 31( 1), 7-22.

Spink, M. J. P. (1992). Psicologia da saúde: a estruturação de um novo campo de saber. In F. C. B. Campos (Org.), Psicologia e saúde: repensando práticas. São Paulo: Hucitec.

Starfield, B. (2002). Atenção primária: equilíbrio entre necessidades de saúde, serviços e tecnologia. Brasília: UNESCO, Ministério da Saúde.

Traverso-Yépez, M. (2001, jul./dez.). A interface psicologia social e saúde: perspectivas e desafios. Psicologia em Estudo, 6(2), 49-56.

Vasconcelos, E. M. (fev. de 2001). Redefinindo as práticas de saúde a partir de experiências de educação popular nos serviços de saúde. Interface - Comunicação, Saúde, Educação, 5(8), 121-126.

Vasconcelos, E. M. (2009). Para além do controle social: a insistência dos movimentos sociais em investir na redefinição das práticas de saúde. In S. Fleury, \& L. V. C. Lobato (Orgs.), Participação, democracia e saúde. Rio de Janeiro: CEBES.

Yamamoto, O. H. (2003). A questão social e políticas públicas: revendo o compromisso da Psicologia. In A. Bock (Org.), Psicologia e compromisso social. São Paulo: Cortez.

Westphal, M. F., \& Santos, J. L. F. (1999). Práticas emergentes de um novo paradigma em saúde: o papel da universidade. Estudos Avançados, 13(35), 71-88. 